\title{
Aspects regarding the explosion risk assessment of installations in atmospheres with combustible dust
}

\author{
Cătălin Mihai Popa $^{1 *}$, Florin Adrian Păun ${ }^{1}$, and Dan Sorin Gabor ${ }^{1}$ \\ ${ }^{1}$ National Research and Development Institute for Mining Safety and Explosion Protection - \\ INSEMEX, G-ral Vasile Milea Street, no. 32-34, Postal code: 332047, Petrosani, Hunedoara County, \\ Romania
}

\begin{abstract}
Many industrial processes involving the presence of dust and combustible dust, suspended or accumulated in the form of deposits, have the potential to lead to a fire, explosion or decomposition in the presence of oxygen. As the damage caused by an explosion of dust is generally greater than that caused by explosions of flammable gases and vapours, a special attention must be paid to measures and means of protection and prevention of explosions of dust.

A dust explosion can only occur if there is mainly a potentially explosive atmosphere generated by the air / dust mixture and a source of ignition.

The level of safety is given by the operational efficiency of the employees and technical equipment involved in the production process to ensure that at least one of the above conditions is eliminated. The probability of a dust explosion is related to the physicochemical properties of the processed materials, together with the nature of the operations performed and the equipment used.

This paper highlights the principles and factors that must be taken into account when conducting an explosion risk assessment in installations with combustible dust atmospheres in order to establish prevention and protection measures, with the aim of ensuring a tolerable level of risk.
\end{abstract}

\section{Introduction}

Many industrial processes involving the presence of dust and combustible dust, which are in suspension or which are deposited in layers or dust deposits, have the potential to lead to a fire, explosion or decomposition in the presence of oxygen.

Every year there are many serious fires and even explosions that can have devastating effects in industrial installations where combustible dusts are present, materialized by considerable material damage, long production shutdowns or even loss of life.

The danger of explosion in workplaces where potentially explosive atmospheres from the mixture of combustible dusts with air may form must, in all cases, be treated as a major hazard, as explosions which may occur may seriously affect both health and safety. people,

* Corresponding author: mihai.popa@insemex.ro 
as well as the environment. For this reason, it is necessary to adopt precautionary measures appropriate to each situation in order to ensure the prevention and protection against explosions, which can be developed following an assessment of the existing risk of explosion.

The danger of explosion is related both to the hazardous materials and substances in the form of dust involved in the production process, used or released by the technical equipment on the technological flow, protection systems and components, and to the materials used to make the equipment, protection systems and components.

An explosive atmosphere of combustible dust is defined as a mixture with air of combustible dusts, powders or flakes, a mixture in which, after ignition, combustion is transmitted into the entire unburned mixture. [1]

An explosion occurs when combustible dusts are present in suspension in admixture with air in the explosive range of those dusts, i.e. between their lower explosive limit (LEL) and upper explosive limit (UEL), at the same time an ignition source whose starting energy is high enough to ignite the air / dust mixture formed. The explosion of combustible dusts occurs if there is a simultaneous interaction of the combustible substance with the oxidant and the ignition source, taking into account the aspects related to the closure of the mixture, thus resulting in the so-called pentagon explosion, shown in Figure 1. [2], [3], [4].

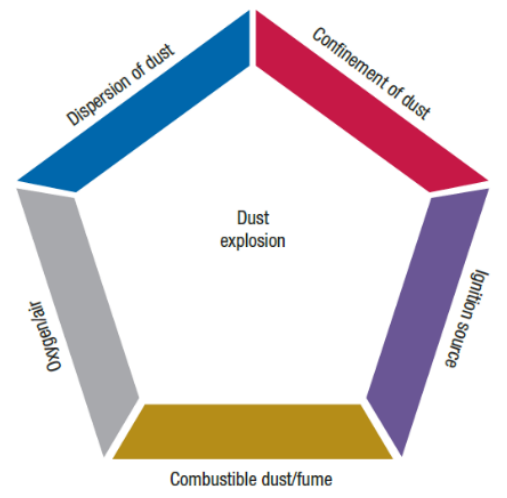

Fig.1. - Pentagon of explosion

The dynamics and violence of a dust explosion depend on several factors, among which we mention:

$\checkmark \quad$ The combustible dust proper (its chemical composition) - characterized by the specific constant of the respective dust $\mathrm{k}_{\mathrm{st}}$, also called explosion index, and which represents the explosive value measure of the combustible dust. Depending on the explosion index, the combustible dusts are classified in four explosion classes, as can be seen in table no. 1 .

Table 1. Classification of combustible dusts according to $\mathrm{k}_{\mathrm{st}}$.

\begin{tabular}{|c|c|c|}
\hline Dust Explosion Class & Kst [bar $\times \mathbf{m} / \mathbf{s}]$ & Characteristic \\
\hline St 0 & 0 & No explosion \\
\hline St 1 & $>0 \div 200$ & Weak explosion \\
\hline St 2 & $>200 \div 300$ & Strong explosion \\
\hline St 3 & $>300$ & Very strong explosion \\
\hline
\end{tabular}

$\checkmark$ Concentration of dust mixed with air - depending on this a potentially explosive atmosphere may form. If the concentration is too low or too high, no explosion occurs, but there may be only a slow combustion reaction or even no combustion. Thus, the explosion can only occur if the concentration of combustible dust is within the explosive range of that combustible dust. In general, in the case of combustible dusts, the lower explosive limit is between 20 and $60 \mathrm{~g} / \mathrm{m}^{3}$, while the upper explosive limit is between 2 and $6 \mathrm{~kg} / \mathrm{m}^{3}$. 
The size of dust particles plays an important role in determining the severity of an explosion, because the finer the dust particles, the less they weigh and tend to remain suspended in the air for a longer period of time.

Aspects regarding the homogeneity of dust clouds and the way the dust particles are presented, namely: particle shape, particle size distribution, combustion chemistry, presence of contaminants (such as vapours, gases or inert gases), atmospheric turbulence, moisture content of particles.

$\checkmark \quad$ Cleaning of areas endangered by the presence of combustible dust. If systematic cleaning is not carried out in accordance with a cleaning plan, suspended dust particles are deposited on floors, walls or equipment, leading in time to the formation of layers or deposits of dust of different thicknesses. These layers or deposits of dust, in the event of an explosion, can be swirled, thus providing the fuel needed for other secondary explosions.

\section{Elimination or minimization of the risk of explosion}

\subsection{Principles of explosion prevention and explosion protection [5]}

The basic principles for explosion prevention and protection derive from the need for coincidence of the explosive atmosphere and the effective source of initiation, as well as from the analysis of the expected effects of an explosion, which can be addressed in the following order:

a) explosion prevention - is a concept that materializes through:

$>$ avoiding the appearance of explosive atmospheres. This objective can be achieved either by changing the concentration of combustible dust which, when mixed with air, gives rise to an explosive atmosphere, to a value which is outside the range of explosiveness, or by changing the concentration of oxygen to a value below the oxygen limit (LOC). This can be achieved within the parameters of production processes by using combustible dust substitutes, limiting concentrations, preventing or limiting the production of explosive atmospheres near the plant, and by designing and constructing technical equipment, protective systems and components in such a way that reduce combustible dust emissions and ensure dilution by ventilation.

$>$ avoiding all possible efficient sources of burning.

b) explosion protection - can be achieved by:

$>$ establishing and implementing protection measures to reduce the effects of explosion, such as: explosion-proof design of equipment, release of explosion pressure, suppression of explosion, prevention of flame spread and explosion. In this case, unlike the two measures that can be applied to the concept of prevention, it is acceptable to produce an explosion.

Elimination of the risk of explosion or reduction to an accepted level can be achieved by implementing only one of the principles of protection and prevention set out above. However, there are also situations in which a combination of these principles can be applied.

Always, the first option would be to avoid the appearance of a potentially explosive atmosphere, because the higher of an explosive atmosphere probability occurring, the greater should be the extension of the measures to be taken against the emergence of effective ignition sources.

In conclusion, the requirement to prevent explosions can be expressed in the following form: the probability that a source of ignition will occur simultaneously with an explosive atmosphere is minimal. From this requirement derives the need to establish specific requirements that apply to technical equipment and protective systems depending on the specified field of use. 
In order to allow the selection of appropriate precautions, a concept of explosion safety must be developed for each case, by following the steps below.

\subsection{Hazardous Ex areas classifications generated by combustible dusts, fibres or cloth}

Hazardous area classification is a way of analysing and classifying workplaces in industrial installations where combustible dusts are present, in relation to the probability of the formation of explosive dust / air mixtures and the deposition of combustible dusts in the layer. This analysis is primarily used for the correct selection of technical equipment intended to be used safely in such a hazardous environment, taking into account the characteristics of the dust.

In order to classify hazardous areas where explosive air / dust mixtures are present, it is necessary to specify exactly the nature of the dust, the technical installations that are present, and the following steps must be completed:

- Identification of the main characteristics of combustible dust: size of dust particles, their humidity, minimum ignition temperature in the cloud and layer, electrical resistivity, as well as the corresponding dust group (group IIIA - combustible cloth, group IIIB - non-conductive dust, group IIIC - dust conductive);

- Identifying the spaces and workplaces where combustible dusts or sources of their release may be present, as well as identifying the possibilities for the formation of dust layers;

- Analysis of the probability of explosive dust / air mixtures occurring in different parts of the technical installation.

According to SR EN 60079-10-2:2015 [6], Ex classified areas for explosive dust atmospheres are divided into zones, which are identified and classified according to the frequency and duration of the explosive dust atmosphere, as follows:

- Zone 20: A place where an explosive atmosphere of dust in the form of a cloud of dust in the air is present continuously or for long periods of time or frequently.

- Zone 21: A place where an explosive atmosphere of dust in the form of a cloud of dust in the air is likely to occasionally occur during normal operation.

- Zone 22: A place where an explosive atmosphere of dust in the form of a cloud of dust in the air is not likely to occur during normal operation, but which, if it occurs, will persist only for a short period of time.

\subsection{Establish the zoning plan and the appropriate location of the warning signs}

In accordance with European Directive 1999/92/EC [7], all workplaces where combustible dusts and/or powders are present, and where, by default, potentially explosive atmospheres may occur, must be classified in zones by the employer. Also, in places where potentially explosive atmospheres may occur, the warning sign "Ex" must be displayed at the entrance.

These warning signs must comply with the requirements laid down in European Directive 1999/92/EC as regards shape, colour, proportions and additional information may be displayed, where applicable.

\subsection{Prevention of ignition sources}

Combustible dusts and powders may be ignited by several sources of ignition, which may be of an electrical or mechanical nature, of which we mention:

- hot surface;

- electric springs that may appear in switches, contacts, brushes, etc. 
- electrostatic discharge;

- thermal sparks;

- mechanical or frictional sparks;

In order to avoid the occurrence of efficient ignition sources or to mitigate their effect, a series of explosion protection measures may be adopted and implemented, including: the choice of electrical and non-electrical equipment operating in locations with combustible dust hazards. type of protection Ex appropriate to those areas.

Tables 2 and 3 shows the types of Ex protection that technical equipment in hazardous areas with combustible dust may present, as well as their selection according to the areas classified Ex.

Table 2. Types of explosion protection for electrical equipment in dusty areas

\begin{tabular}{|c|c|c|c|}
\hline $\begin{array}{l}\text { Types of protection / } \\
\text { reference standard }\end{array}$ & $\begin{array}{l}\text { Category } 1 \\
\text { EPL a } \\
\text { Very high level of } \\
\text { protection }\end{array}$ & $\begin{array}{l}\text { Category } 2 \\
\text { EPL b } \\
\text { High level of } \\
\text { protection }\end{array}$ & $\begin{array}{l}\text { Category } 3 \\
\text { EPL c } \\
\text { Normal level of } \\
\text { protection }\end{array}$ \\
\hline & $\begin{array}{l}\text { USE } \\
\text { Zone } 20 \\
\text { Zone } 21 \\
\text { Zone } 22\end{array}$ & $\begin{array}{l}\text { USE } \\
\text { Zone } 21 \\
\text { Zone } 22\end{array}$ & $\begin{array}{l}\text { USE } \\
\text { Zone } 22\end{array}$ \\
\hline $\begin{array}{l}\text { Optical radiation } \\
\text { interlocked with } \\
\text { optical breakage } \\
\text { SR EN IEC } 60079-28\end{array}$ & - & Ex op sh & - \\
\hline $\begin{array}{l}\text { Intrinsic safety Ex i } \\
\text { SR EN IEC 60079-11 } \\
\text { SR EN IEC 60079-25 } \\
\text { systems }\end{array}$ & Ex ia & Ex ib & Ex ic \\
\hline $\begin{array}{l}\text { Inherently safe optical } \\
\text { radiation } \\
\text { SR EN IEC 60079-28 }\end{array}$ & Ex op is & - & - \\
\hline $\begin{array}{l}\text { Encapsulation Ex m } \\
\text { SR EN IEC 60079-18 }\end{array}$ & Ex ma & Ex mb & $\begin{array}{l}\text { Ex mc } \\
\text { Ex n* }\end{array}$ \\
\hline $\begin{array}{l}\text { Pressurised enclosure Ex p } \\
\text { SR EN IEC 60079-2 }\end{array}$ & - & Ex pxb, Ex pyb & Ex pzc \\
\hline $\begin{array}{l}\text { Protection using enclosure } \\
\text { Ex t } \\
\text { SR EN IEC 60079-31 }\end{array}$ & Ex ta & Ex tb & Ex tc \\
\hline $\begin{array}{l}\text { Protected optical radiation } \\
\text { SR EN IEC 60079-28 }\end{array}$ & - & Ex op pr & - \\
\hline
\end{tabular}

Table 3. Types of explosion protection for nonelectrical equipment in dusty areas

\begin{tabular}{|c|c|c|c|}
\hline $\begin{array}{l}\text { Types of protection / } \\
\text { reference standard }\end{array}$ & $\begin{array}{l}\text { Category } 1 \\
\text { EPL a } \\
\text { Very high level of } \\
\text { protection }\end{array}$ & $\begin{array}{l}\text { Category } 2 \\
\text { EPL b } \\
\text { High level of } \\
\text { protection }\end{array}$ & $\begin{array}{l}\text { Category } 3 \\
\text { EPL c } \\
\text { Normal level of } \\
\text { protection }\end{array}$ \\
\hline & $\begin{array}{l}\text { USE } \\
\text { Zone } 20 \\
\text { Zone } 21 \\
\text { Zone } 22\end{array}$ & $\begin{array}{l}\text { USE } \\
\text { Zone } 21 \\
\text { Zone } 22\end{array}$ & $\begin{array}{l}\text { USE } \\
\text { Zone } 22\end{array}$ \\
\hline
\end{tabular}




\begin{tabular}{llll}
\hline $\begin{array}{l}\text { Constructional safety } \\
\text { SR EN IEC 80079-37 }\end{array}$ & Ex h & Ex h & Ex h \\
\hline $\begin{array}{l}\text { Control of ignition source } \\
\text { SR EN IEC 80079-37 }\end{array}$ & Ex h & Ex h & Ex h \\
\hline $\begin{array}{l}\text { Liquid immersion } \\
\text { SR EN IEC 80079-37 }\end{array}$ & Ex h & Ex h & Ex h \\
\hline $\begin{array}{l}\text { Pressurised enclosure Ex } \\
\text { p }\end{array}$ & - & Ex pxb, Ex pyb & Ex pzc \\
SR EN IEC 60079-2 & & & \\
\hline $\begin{array}{l}\text { Protection by enclosures } \\
\text { Ex t }\end{array}$ & Ex ta & Ex tb & Ex tc \\
SR EN IEC 60079-31 & & & \\
\hline
\end{tabular}

\subsection{Selection of technical equipment}

Technical equipment intended for operation in hazardous areas with combustible dust must be selected on the basis of the classification of Ex hazardous areas, the combustible dusts present, their ignition temperatures and the environmental characteristics of the sites of the installation to which they belong.

This selection will be made taking into account the category of equipment that must be appropriate for the type of classified area, depending on the level of protection required in accordance with the criteria presented in table 4.

Table 4. Selection of technical equipment intended for areas with combustible dust

\begin{tabular}{|c|c|c|c|c|c|}
\hline ZONE & $\begin{array}{c}\text { Presence of the } \\
\text { explosive } \\
\text { atmosphere } \\
\text { (explosion hazard) }\end{array}$ & $\begin{array}{c}\text { Avoidance of effective } \\
\text { ignition sources } \\
\text { (ignition hazard) }\end{array}$ & $\begin{array}{c}\text { Required } \\
\text { level of } \\
\text { protection }\end{array}$ & $\begin{array}{c}\text { Group II } \\
\text { CATEGORY }\end{array}$ & EPL \\
\hline $\mathbf{2 2}$ & $\begin{array}{c}\text { Infrequently and for } \\
\text { a short period only }\end{array}$ & $\begin{array}{c}\text { During normal } \\
\text { operation }\end{array}$ & NORMAL & $3 \mathrm{D}$ & $\mathrm{Dc}$ \\
\hline $\mathbf{2 1}$ & Likely to occur & $\begin{array}{c}\text { Also during foreseeable } \\
\text { malfunctions (single } \\
\text { fault) }\end{array}$ & HIGH & $2 \mathrm{D}$ & $\mathrm{Db}$ \\
\hline $\mathbf{2 0}$ & $\begin{array}{c}\text { Continuously, for } \\
\text { long periods or } \\
\text { frequently }\end{array}$ & $\begin{array}{c}\text { Also during rare } \\
\text { malfunctions (two } \\
\text { independent faults) }\end{array}$ & VERY & $1 \mathrm{D}$ & $\mathrm{Da}$ \\
\hline \multicolumn{3}{|c|}{ MANUFACTURERS } & \\
\hline $\begin{array}{c}\text { Directive 1999/92/EC } \\
\text { (HG 1058/2006) }\end{array}$ & \multicolumn{4}{|c|}{ Directive 2014/34/EU } \\
(HG 245/2016)
\end{tabular}

\section{Ignition risk assessment for bucket elevators}

The potentially explosive atmospheres probability, the ignition sources presence and the effective ignition will determine the fire or explosion probability. The bucket elevator location and the adequate protection systems presence will determine the fire or explosion consequences. 
The combustible dust ignition in the case of a bucket elevator may result in a smouldering fire, a blazing fire, an explosion or a propagating explosion. Following a dust explosion, there is a possibility that a fire may continue inside or outside the bucket elevator.

The explosion danger in bucket elevators depends very much on the nature and appearance of the bulk material. In this case, a decisive role is played by the fine fraction of the bulk material, with particle sizes smaller than $500 \mu \mathrm{m}$, and how easily a cloud of dust is formed. Always, if a bulk material contains relevant fractions of dust in its composition, an explosion hazard must be assumed.

Even of low dust concentrations, over time, the dust can adhere to the bucket elevator housing, leading to the formation of layers with a thickness of a few millimetres. These layers of dust adhering to the elevator housing are not in themselves explosive mixtures, but constitute a continuous potential for an explosive mixture - for example, due to bucket elevator failures (non-alignment of the belt), the housing may vibrate, which it leads to the turbulence of the adhering dust and its dispersion in the form of an explosive dust cloud.

Explosion risk assessment is difficult to perform in the case of a bucket elevator. Normally, the bucket elevator user chooses it according to its category and then, will perform a risk analysis and assessment according to local circumstances.

In principle, the fire and explosion danger analysis in the case of a bucket elevator can be performed by following the logic diagram shown in Figure 2.

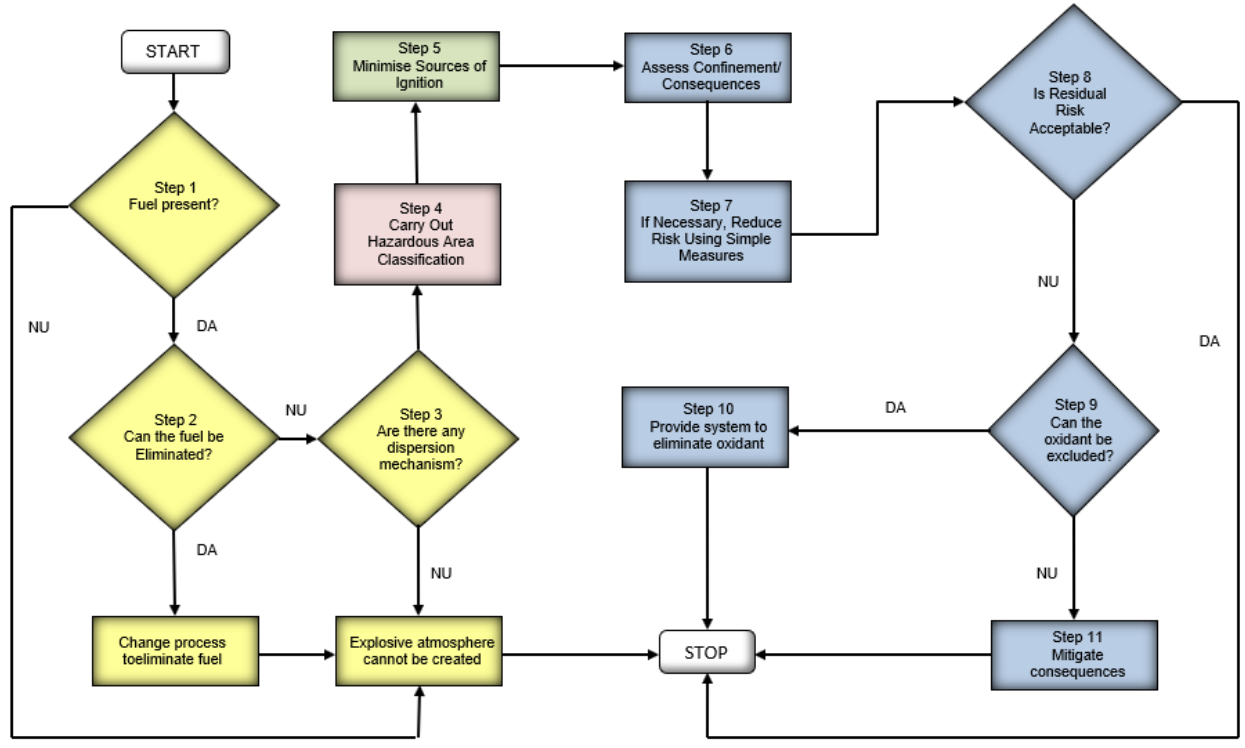

Fig. 2. The explosion risk logic diagram

As can be seen, if combustible dust is present, after the hazardous areas classification has been carried out, it is first necessary to identify all ignition sources and to check whether the protection measures adopted and implemented prevent the occurrence efficient ignition sources, as follows:

- during normal operation, if the potential ignition source is in zone 22;

- also during foreseeable failures (for a single failure), if the ignition source is in Zone 21;

- also during rare failures (two independent failures) if the ignition source is in Zone 20.

Depending on the acceptability of the risks, in addition to preventive measures, based on the bucket elevator category, it may be necessary to adopt and implement certain explosion protection measures. 
From the point of view of the existence of potential ignition sources, in the case of bucket elevators, the following initiation sources can be found:

Equipment ignition sources - are presented in table 5.

Table 5. Equipment ignition sources

\begin{tabular}{|l|l|}
\hline $\begin{array}{c}\text { Potential ignition } \\
\text { sources }\end{array}$ & \multicolumn{1}{c|}{ Possible causes } \\
\hline Hot surfaces & $\begin{array}{l}\text { - Bucket lifting belt friction with elevator housing wall due to } \\
\text { misalignment } \\
\text { - Friction between the lift belt and the drive wheel (drum) due to } \\
\text { slipping } \\
\text { - Friction of loose parts in the elevator with buckets (loose bucket, } \\
\text { lost pulley parts, etc.) with moving parts } \\
\text { - Damage to bearings and gears }\end{array}$ \\
\hline Mechanical sparks & $\begin{array}{l}\text { - Mechanical sparks due to cups colliding with the housing wall (due } \\
\text { to insufficient belt tension, defective belt, loose cups) or with the } \\
\text { discharge chute } \\
\text { - Non-alignment of the drive wheel }\end{array}$ \\
\hline $\begin{array}{l}\text { Electrical } \\
\text { equipment }\end{array}$ & $\begin{array}{l}\text { - Electrical equipment and motors } \\
\text { - Improper grounding and / or equipotential bonding }\end{array}$ \\
\hline Electrostatics & $\begin{array}{l}\text { - Electrostatic charging due to the separation processes between the } \\
\text { belts and the drive pulleys } \\
\text { - Electrostatic charging of cups due to electrostatic induction } \\
\text { •Electrostatic charging of any other installed conductive components } \\
\text { that is not grounded }\end{array}$ \\
\hline
\end{tabular}

Ignition sources introduced or acting from the outside

Bucket elevators that are part of an installation configuration have interfaces that should also be considered. This means that ignition sources that can be introduced into bucket elevators must be considered in addition to ignition sources related to equipment.

A potential typical ignition sources summary introduced or acting from the outside is presented in table 6 .

Table 6. Ignition sources introduced or acting from the outside

\begin{tabular}{|l|l|}
\hline Potential ignition sources & Possible causes \\
\hline Hot surfaces & $\begin{array}{l}\text { - Foreign material introduction } \\
\text { - Incandescent particles introduction } \\
\text { - Welding, grinding, cutting operations } \\
\text { - Damage to the housing due to external mechanical } \\
\text { action }\end{array}$ \\
\hline $\begin{array}{l}\text { Hot flames and gases, including } \\
\text { hot particles }\end{array}$ & $\begin{array}{l}\text { - Incandescent particles introduction } \\
\text { - Fire or explosion propagation from connected or } \\
\text { external installations }\end{array}$ \\
\hline Mechanical sparks & $\begin{array}{l}\text { - Foreign material introduction } \\
\text { - Damage to the housing due to external mechanical } \\
\text { action }\end{array}$ \\
\hline Lightning & - Inadequate lightning protection \\
\hline
\end{tabular}


Ignition sources from the product itself

There are also possible ignition sources arising from the product itself. Therefore, it must be checked whether self-ignition or exothermic decomposition is expected due to the characteristics of the bulk material.

Such exothermic reactions should be assumed to occur in particular in installations operating at high temperatures and in which large dust accumulations are formed either intentionally (storage, intermediate storage, etc.) or unintentionally (deposits, agglomerations).

In the case of organic products (such as cereals), an excessive moisture content may also present the risk of self-ignition due to microbiological processes (Maillard reaction).

In bucket elevators, large products accumulations can occur in the feed base and in the horizontal feed and outlet sections. It should be noted here that the self-ignition or degradation temperature, which is a characteristic of the self-heating behaviour of any dust, will decrease as the volume and thickness of the layer increase. Incandescent nests and selfigniting flames can become ignition sources for dust explosions when deposits are turbulent.

Especially in the case of bulk organic materials, there is the additional burning danger before self-ignition, which can release combustible gases such as carbon monoxide which when mixed with wood dust leads to the formation of hybrid mixtures.

\section{Conclusions}

The ignition and explosion risk assessment, in the case the use of technical equipment and protective systems in environments where combustible dusts are present which may cause fires and explosions, is of particular importance with regard to ensuring the health and safety of workers involved in the production process. In accordance with the legislation in force, the risk assessment and the adoption of the necessary protection measures to ensure an acceptable level of safety is a responsibility of both equipment manufacturers and their users.

In this regard, it is necessary that all technical equipment in an installation operating in environments with potentially explosive atmospheres generated by the dust / air mixture be subjected to a risk analysis, identifying all potential ignition sources and all protection measures to be adopted and implemented to prevent potential ignition sources from becoming effective.

The technical equipment used must be selected on the basis of the hazardous area classification in the three zones 20, 21 and 22, the existing combustible dusts, the ignition temperatures, the installation site environmental characteristics and taking into account the equipment category to be appropriate for the classified area type.

\section{References}

1. Standard EN 1127-1 (2019)

2. G.A. Găman, M. Popa, sa., „National guide on establishing occupational safety and health requirements for economic operators operating with substances / products / goods capable of generating explosive / toxic atmospheres, or having detonating / explosive characteristics”, Editura INSEMEX, Petroșani, România, ISBN 978-606-8761-26-8 (2018)

3. M. Popa, S. M. Nan, M. Părăian, A. Jurca, F. Păun, L. Lupu, N. Vătavu, D. Gabor, Study of explosive characteristics of combustible powders, 8th International Multidisciplinary Scientific Symposium „UNIVERSITARIA SIMPRO” 11-13 October 2018, Petroşani, România, Conference Proceedings ISSN-L 1842 - 4449, ISSN 2344 - 4754 (2018) 
4. A. Jurca, F.A. Păun, M. Părăian, D. Gabor, L. Lupu, Study of influence factors of determination the explosive characteristics to the air / combustible dust mixtures, 18th International Multidisciplinary Scientific Geoconference (SGEM 2018), Mineral processing, Oil and Gas Exploration, Bulgaria, vol. 18, pp. 819-826, (2018)

5. Directive 2014/34/EU (2014)

6. Standard EN 60079-10-2 (2015)

7. Directive 1999/92/EC (2000) 